\title{
The Effect of Capital Market Concerns on Specific Investments in the Supply Chain*
}

\author{
Hui Chen \\ Thomas Pfeiffer \\ University of Zurich \\ University of Vienna
}

November, 2019

\begin{abstract}
The financial market gives significant consideration to supply chain activities of publiclylisted firms, who could in turn use their investments in the supply chain to manage market expectations. We study the effects of the capital market concerns of a publiclytraded retailer that collaborates with a privately-owned supplier in a supply chain. The firms each undertake a relation-specific investment and then bargain over the joint surplus generated by the collaboration. The retailer's market concerns make it a more aggressive bargainer, and able to obtain a higher share of the joint surplus. The investments of both firms increase with the retailer's market concerns when the retailer's investment is sufficiently important for the collaboration. In this case, the retailer benefits from its market concerns. When the supplier's investment is sufficiently important, both firms invest less and the retailer suffers from its market concerns. From the perspective of the whole supply chain, the retailer's market concerns could mitigate or exacerbate the hold-up problem between the two firms and thus could be either beneficial or detrimental. In the extension, we also discuss the observability of the firms' investment decisions as well as the case of two symmetric firms that are both publicly traded.
\end{abstract}

Keywords: hold-up, specific investment incentives, capital market valuation, supply chain

*The authors' emails are hui.chen@business.uzh.ch and thomas.pfeiffer@univie.ac.at. We thank Anil Arya, Sunil Dutta, Brian Mittendorf, Alexander Nezlobin, Alfred Wagenhofer (discussant), Xiao-Jun Zhang, and workshop participants at the University of California at Berkeley and at the German Economic Association of Business Administration Conference for helpful comments. All errors are our own. 


\section{Introduction}

Supply chain activities are an important part of the firm value. The financial market gives significant consideration to supply chain activities of publicly-listed firms. ${ }^{1}$ In this paper, we examine how a public firm within a supply chain manages its stock market expectations through relation-specific investments that increase the value of the supply chain. Specifically, we study a supply chain setting where at least one participating firm is publicly traded and faces pressure from the capital market. We are particularly interested in how this concern for stock price affects the specific investment decisions of the focal firm(s), as well as the subsequent effects on the profitability of the individual firms and the efficiency of the whole supply chain.

It is well known that publicly-traded companies care about their stock performance. In a single firm setting, this concern for capital market could lead the firms to take actions that temporarily inflate market belief but at the expense of the firms' long-term value (Stein 1989). While we also apply a signal jamming model to explore the potential effects of a firm's market concerns, we focus on a supply chain with two firms interacting with each other. Our paper complements the insight of prior literature by showing that one firm's capital market concerns affect not only its own investment decision and efficiency, but also those of its business partner and the whole supply chain. We identify conditions when these effects from market concerns are positive or negative, and show that, under plausible circumstances, market concerns could benefit the individual firms as well as the whole supply chain.

In the baseline model, we consider a supply chain consisting of a publicly-listed retailer and a privately-owned supplier. The game lasts two periods, with both firms liquidated at the end of the second period. The supply chain collaboration between the two firms comprises a significant part of their respective businesses. At the beginning of the collaboration, each

${ }^{1}$ For example, Home Depot recently started investment initiatives in its collaboration with upstream supply chain partners to facilitate a faster and smoother interface with end customers. The stock market reacted very positively and Home Depot's stock price increased significantly, as reported by the Wall Street Journal and Forbes. 
firm must undertake a relationship-specific investment. The technology of the supply chain collaboration follows a Cobb-Douglas function, with the two firms' investments serving as the two production inputs. The output elasticities represent the importance of the respective investment for the collaborative relationship. The investments and the associated costs are unobservable and unverifiable to outsiders including the capital market. The firms then engage in trade and negotiate about the share of the joint surplus that each firm receives. An interim stock price is formed for the retailer at the end of the first period, based on the capital market's expectation of the retailer's long-term cashflow. Due to its myopic concern for stock price, the retailer has an incentive to inflate the market expectation of its future performance. We analyze how the retailer's capital market concerns affect the firms' decisions and subsequent profitability.

We show that the retailer's market concerns make it a more aggressive bargainer during the negotiation process. This is intuitive, as the retailer now has a higher stake to negotiate for. Consequently, the retailer's share of trading surplus from the supply chain collaboration increases in its degree of market concerns, while the share of trading surplus for the supplier decreases in the retailer' market concerns. However, the retailer's concern for the stock market price do not necessarily render it to make a higher investment. Depending on the relative importance of the two firms' investments in their joint business, the retailer's incentive to invest may increase or decrease. In particular, if the supplier's investment is sufficiently more important than the retailer's investment in the collaboration, the retailer with market concerns would make an investment lower than without market concerns. This result obtains because the retailer's aggressive bargaining leaves the supplier less incentivized to invest in the collaboration. Given that the supplier's investment is more critical for the collaboration, its dampened incentive is anticipated by the retailer who then also reduces its own investment due to the inherent complementarity between the two investments. In contrast, when the retailer's investment is sufficiently more important for the supply chain 
collaboration, the complementarity implies that the investments of both firms increase in the retailer's market concerns.

The retailer's market concerns affect both the total size and the allocation of the trading surplus generated by the supply chain. While the market concerns always help the retailer in securing a bigger share of the supply chain surplus, its effect on the total size of the surplus can be both positive and negative, depending on the investment decisions of the two firms. The market concerns lead to higher payoff for the retailer when its own investment is sufficiently more important than the supplier's investment. In this case, the retailer obtains a bigger piece of a larger pie as it benefits from both increased total surplus and a bigger share of that surplus. This result complements conventional wisdom from signal jamming models in a single-firm setting that typically suggest myopic market concerns are detrimental by generating wasteful investments. The retailer's market concerns could also result in a lower payoff when the supplier's investment is significantly more important than the retailer's. Under such circumstances, the retailer still receives a higher share of the trade surplus but the total surplus is smaller due to the underinvestments. In this case, the retailer can be worse off in the presence of market concerns.

From the perspective of the whole supply chain, a classical hold-up problem arises when the retailer does not face any market concerns. That is, both firm underinvest as they each have to bear the full cost for the respective investment, but cannot receive the full benefits. The effect of the retailer's market concerns on the efficiency of the whole supply chain depends on the relative importance of these investments. When the retailer's investment is sufficiently more important, the firms make higher investments, which mitigates the hold-up problem and improves supply chain efficiency. However, the retailer's market concerns cannot lead the firms to make optimal investments at first-best level. Thus the supply chain efficiency cannot be restored just through the market concerns alone. ${ }^{2}$ The retailer's market concerns,

\footnotetext{
${ }^{2}$ First-best efficiency for the supply chain can only be achieved in the scenario when only the retailer's investment is needed and the supplier's is not. There exists a level of a retailer's market concerns that results in the first-best investment.
} 
however, are not always beneficial. If the supplier's investment is sufficiently more important than the retailer's investment, the retailer's market concerns can also induce underinvestment and results in detrimental effect for the whole supply chain.

We then examine the effect of observability of the firms' investments, which is a critical assumption of the signal jamming models. The capital market in Stein (1989) anticipates the manager to inflate the firm value and the manager indeed takes such an action. In equilibrium, the capital market is not fooled and all players are trapped in this "bad" equilibrium. Should the manager's action be observable, the capital market would simply update its belief accordingly and the signal jamming would no longer hold. In our setting, signal jamming induces a potentially "good" equilibrium as it could lead the firms to make higher investments, thus the supply chain firms can actually benefit from the lack of observability. We identify conditions under which the retailer, the supplier, and the entire supply chain could be better off when the capital market does not observe the firms' investments and negotiation outcome.

Finally, we also study the case where both firms are publicly listed. We allow the firms to be symmetric by sharing the same levels of bargaining power, importance in the collaboration, and market concerns. Similar to the case with one public firm and one private firm, the market concerns influence the firms' investments, the shares of joint surplus received, and the payoffs. We show that a certain degree of market concerns is beneficial for the firms themselves as well as for the whole supply chain.

Our paper is closely connected to the well established literature on hold-up problems, including Grossman and Hart (1986), Hart (1995), Hart and Moore (1999), and Segal and Whinston (2012), among others. This literature takes the perspective of the welfare of the whole partnership and studies how a potential hold-up between individual parties can result in the undersupply of relation-specific investments and inefficiencies for the all parties involved. This idea has been widely applied to a variety of different inter- and intra-firm 
coordination problems. Of particular interest thereby is how different agreements exacerbate or mitigate the hold-up problem between the parties (e.g., Edlin and Reichelstein 1995, 1996, Noldeke and Schmidt 1995, Anctil and Dutta 1999, Baldenius and Reichelstein 1999, Arya, Fellingham, Glover, and Sivaramakrishnan 2000, and Taylor and Plambeck 2007). Our paper shows how the market concerns of a publicly-listed firm affect the investments of the parties, the distribution of the joint surplus, and the performance of the individual parties and the whole supply chain.

Our paper is also closely related to the signal jamming literature, including Holmstrom (1983), Gibbons (1985), Fudenberg and Tirole (1986), Stein (1989) among others. Signal jamming is a type of model that results in an equilibrium in which the sender of information always manipulates while the receiver of information always anticipates the manipulation. Holmstrom (1983) shows that career concerns at the labor market provide incentives for an employee to overexert effort in the early stage of his career, in order to raise the labor market's assessment of his ability. Stein (1989) describes a scenario where managers with myopic preference for a higher stock price engage in nonproductive actions/investments to manipulate market expectation. Signal jamming models are also applied in accounting research. A review provided by Kanodia and Sapra (2016) highlights how different accounting treatments of performance measures interact with the firm's investment decisions in the presence of capital market concerns. Liang and Wen (2007) show firms may over- or underinvest depending on how the accounting system measures the firms' cash flows and investments. Kanodia, Singh, and Spero (2005) show that some imprecision in measuring a firm's investment can be beneficial when the profitability of the investment cannot be directly communicated to the capital market. Dutta and Nezlobin (2019) show that risk-averse shareholders can benefit from the non-disclosure of the firm's investment decision.

Finally, our paper is especially similar in spirit to studies that examine the impact of a firm's market concerns within a supply chain. Lai, Debo, and Nan (2011) examine how 
a myopic manager of a retailer may use channel stuffing to mislead the market valuation. The manager reports a sales level that is higher than the actual demand by pushing leftover inventory to downstream firms. Based on the signaling framework, Lai, Xiao, and Yang (2012), Schmidt, Gaur, Lai, and Raman (2015), and Lai and Xiao (2018) examine the effect of inventory stocking decisions in a newsvendor model to signal a firm's private information about its expected consumer demand to the capital market.

Our analysis contributes to the prior literature by showing that public firms' concerns for stock market performance could have a positive effect in a supply chain setting. In particular, when the investment made by the firm with market concerns are sufficiently important for the collaboration, the market concerns help mitigating the hold-up problem and the inefficiency associated with it. By taking this approach, we also add to the limited prior studies that investigate the impact of the capital market on supply chain management. Many firms active in supply chains are publicly-traded and care about their stock market performances. However, the majority of supply chain research focuses on the firms' operational efficiency, while remaining silent on the importance of capital market concerns in the firms' operational decisions. Our paper demonstrates one such scenario and how the market concerns could affect not only the focal firm but also the whole supply chain. Finally, our analysis can be recast in terms of a strategic alliance or a joint venture between two firms. As long as bilateral investments are needed and market concerns are present, the insights from our results would hold true.

The paper is organized as follows: Section 2 describes the baseline model that is analyzed in Section 3. Section 4 analysis the case that the capital market has perfect information about the firms' decisions. Section 5 analysis the case that both firms are listed. Section 6 concludes the paper. All proofs are relegated to the appendix. 


\section{Setup}

We consider a retailer $(R)$ and a supplier $(S)$ who form a supply chain, with the supplier providing input for the retailer who then sells the product to the final consumer market. The supplier is privately owned while the retailer is publicly traded. The key difference between the two firms is that the retailer cares not just only about the its long-term cashflows, but also about short-term stock price.

While our analysis focuses on the business related to the supply chain collaboration, both firms also independently generate profits from their own regular business in each of the two periods. We denote these net profits as $\tilde{\pi}_{1 R}, \widetilde{\pi}_{2 R}, \tilde{\pi}_{1 S}, \tilde{\pi}_{2 S}$, with all of them normally distributed with means $\mu_{R}$ and $\mu_{S}$, and variances $\sigma_{R}^{2}$ and $\sigma_{S}^{2}$. The profits from the two different periods are correlated, with $\operatorname{Cov}\left[\tilde{\pi}_{1 R}, \tilde{\pi}_{2 R}\right]=\rho_{R}$ and $\operatorname{Cov}\left[\tilde{\pi}_{1 S}, \widetilde{\pi}_{2 S}\right]=\rho_{S}$, and $\rho_{R}$ and $\rho_{S}$ are both positive. This implies that when the first-period profit is high, the second-period profit is also likely to be high. ${ }^{3}$ All other random variables are uncorrelated.

\section{$2.1 \quad$ Time line}

In the beginning of period 1 , the retailer and the supplier each undertake a relation-specific investment at date $1, I_{R}$ and $I_{S}$ respectively, to facilitate the supply chain collaboration. As standard in the hold-up literature, the firms' specific investments are unobservable and unverifiable to outsiders. This is because many supply chain investments involve activities such as market research and technical development, which are inseparable from the firms' regular businesses and difficult to measure and report. To make these investments, the retailer incurs a cost of $w_{R}\left(I_{R}\right)=I_{R}$ and the supplier incurs a cost of $w_{S}\left(I_{S}\right)=I_{S} \cdot{ }^{4}$ The

\footnotetext{
${ }^{3}$ Alternatively, we could let the supply chain business generate a stream of cash flows that are inter-temporally correlated. The firms' investments could serve to enhance these cash flows, on which the financial market forms a price based on its expectations. This alternative scenario would lead to the same qualitative results as the current setting.

${ }^{4}$ It is a standard assumption in both the hold-up literature and the signal jamming literature to have unobservable investments and the associated costs. Our insights remain valid when the costs are observable but with uncorrelated noise, i.e., $w_{R}\left(I_{R}\right)=I_{R}+\eta_{R}$ with $\eta_{R} \sim N\left(0, \sigma_{\eta_{R}}^{2}\right)$ and $\sigma_{\eta_{R}}^{2}>0$ (for a discussion of
} 
collaboration generates a surplus of $M(I)$ with $I=\left(I_{R}, I_{S}\right)$.

For the sake of didactics, we consider a Cobb-Douglas function for the supply chain business model, i.e., $M(I)=I_{R}^{r} I_{S}^{s}$ with $r, s \geq 0$ and $r+s<1$. The parameters, $r$ and $s$, reflect the importance of the retailer's and supplier's investment, respectively. When $r$ is higher than $s$, the retailer's investment is more important for the supply chain collaboration than the supplier's investment (and vice versa). The advantage of the Cobb-Douglas function is that it captures the complementary relation between the firms' investments and provides closed-form solutions.

At date 2, the supply chain partners negotiate about how to divide the surplus generated by the supply chain. As a result of the bargaining process that we describe later, the retailer receives a $\gamma$ share of the surplus and the supplier receives a $(1-\gamma)$ share, with $\gamma \in[0,1]$. The retailer's and the supplier's cash inflows are realized at date 3 and equal

$$
\begin{aligned}
& \widetilde{x}_{1 R}(\gamma, I)=\tilde{\pi}_{1 R}+\gamma M(I) \\
& \widetilde{x}_{1 S}(\gamma, I)=\tilde{\pi}_{1 S}+(1-\gamma) M(I) .
\end{aligned}
$$

In line with the hold-up literature, the investment costs are sunk at that time and are not reflected in the date-3 cashflow. All profits generated during the first period are distributed back to the shareholders. Meanwhile, the stock market updates its information about the retailer and gives a price $p_{R}$.

At period 2, the firms are both liquidated and their liquidation values are simply the cashflows realized, i.e., $\widetilde{x}_{2 R}=\widetilde{\pi}_{2 R}$ and $\widetilde{x}_{2 S}=\widetilde{\pi}_{2 S}$.

this point see Kanodia and Sapra 2016). Section 4 investigates the case that the capital market has perfect information about the investments. 


\section{Figure 1. Timeline of the events.}

\begin{tabular}{lc|c|c|c} 
Period 1 & & Period 2 \\
Date 1 & Date 2 & Date 3 & \multicolumn{2}{c}{ Date 4 } \\
& & & & \\
Investments & Firms bargain & Cashflows & Cashflows \\
made and & on the shares & realized and & realized and \\
costs incurred & of the surplus & price formed & firms liquidated
\end{tabular}

\subsection{Market price and payoffs}

The interim market price for the listed retailer, $p_{R}$, at date 3 reflects the market's expectation of the retailer's future cashflow in period 2, given the market's information $Y^{m}$ in period 1. That is,

$$
p_{R}=E\left[\widetilde{x}_{2 R} \mid Y^{m}\right]
$$

The market's information set is given by $Y^{m}=\left\{x_{1 R}, \widehat{I}, \widehat{\gamma}\right\}$ where " $\wedge$ " denotes the conjectured values of the market. That is, the market observes the period-1 cashflow of the listed retailer and makes conjectures about the investments and the share of the surplus that the retailer receives. In the case where the two firms do not trade the retailer does not receive any surplus, the market simply conjectures $\widehat{\gamma}=0 .{ }^{5}$

The Bayes' theorem for normally distributed random variables implies that $p_{R}$ is determined as the unconditional mean of the period- 2 cashflow plus the realized period-1 cashflow less the conjectured mean for the period-1 cashflow weighted with the familiar covariance-

${ }^{5}$ More formally, we can introduce an additional variable, $\widehat{T} \in\{0,1\}$, that denotes the market conjectures whether the two firms trade or not. However, as $\widehat{T}=0$ is equivalent to setting $\widehat{\gamma}=0$, we use the compressed notation as outlined. 
variance ratio, $\beta_{R}=\frac{\operatorname{Cov}\left[\widetilde{\pi}_{1 R}, \widetilde{\pi}_{2 R}\right]}{\operatorname{Var}\left[\widetilde{\pi}_{1 R}\right]}>0$. That is, the market price equals

$$
p_{R}=E\left[\widetilde{x}_{2 R}\right]+\beta_{R}\left(x_{1 R}(\gamma, I)-E\left[\widetilde{x}_{1 R}(\widehat{\gamma}, \widehat{I})\right]\right)
$$

The realized cashflow, $x_{1 R}(\gamma, I)$, reflects the decisions undertaken by the two firms, whereas the expected cashflow, $E\left[\widetilde{x}_{1 R}(\widehat{\gamma}, \widehat{I})\right]$, reflects the market's conjectures regarding those decisions. If the cash flows of the two periods are uncorrelated, then the market price does not put any weight on the period-1 cash flow and equals the expected period-2 cashflow. With increasing correlation, the period-1 cash flow entails more information about the period- 2 cash flow and the market price puts more weight on the period-1 cash flow.

Accounting for $E\left[\widetilde{x}_{1 R}(\gamma, I)\right]=E\left[\widetilde{\pi}_{1 R}\right]+\gamma M(I)$ and $E\left[\widetilde{x}_{1 R}(\widehat{\gamma}, \widehat{I})\right]=E\left[\widetilde{\pi}_{1 R}\right]+\widehat{\gamma} M(\widehat{I})$ from (1), the expected market price equals

$$
E\left[p_{R}\right]=E\left[\widetilde{x}_{2 R}\right]+\beta_{R}(\gamma M(I)-\widehat{\gamma} M(\widehat{I}))
$$

which increases in the retailer's surplus, $\gamma M(I)$. The retailer thus has an incentive to increase the market price by 1) undertaking high investments and 2) negotiating more aggressively in order to obtain a higher share of the surplus. In equilibrium, however, the market anticipates this behavior and adjusts its conjectures correctly.

Recall that the retailer is motivated by both the firm's interim market price and long-term cashflow, weighted with $\alpha_{R} \in[0,1]$ and $\left(1-\alpha_{R}\right)$, respectively. A common interpretation is that due to life cycle or liquidity reasons a portion $\alpha_{R}$ of the firm may be sold at the capital market before the firm is liquidated and the remaining $\left(1-\alpha_{R}\right)$ portion will be held by the initial shareholders. The parameter, $\alpha_{R}$, reflects the preferences of the shareholders and is exogenously given and not a choice variable. ${ }^{6}$ In particular, the retailer's expected

\footnotetext{
${ }^{6}$ Kanodia and Sapra (2016) provide a more detailed discussion about why short-term incentives arise exogenously. Some other papers treat short-term incentives as an endogenous variable that can be optimized by a judiciously chosen performance-based contract. Since our paper abstract away contracting and incentive issues, we only examine whether a certain level of $\alpha$ is more beneficial for the firms.
} 
total payoff, $E\left[U_{R}\right]$, equals

$$
E\left[U_{R}\right]=\left(1-\alpha_{R}\right) E\left[\widetilde{x}_{2 R}\right]+\alpha_{R} E\left[p_{R}\right]+E\left[\widetilde{x}_{1 R}\right]-w_{R}\left(I_{R}\right)
$$

where $\left(1-\alpha_{R}\right) E\left[\widetilde{x}_{2 R}\right]+\alpha_{R} E\left[p_{R}\right]$ is the weighted average of the long-term period-2 cash flow and the expected interim market price from (4), and $E\left[\widetilde{x}_{1 R}\right]-w_{1 R}$ is the retailer's net payoff for period 1. Accounting for (1) and the expected market price in (4), the retailer's expected total payoff (5) can be restated as follows:

$$
E\left[U_{R}\right]=2 \mu_{R}+\gamma M(I)+\alpha_{R} \beta_{R}(\gamma M(I)-\widehat{\gamma} M(\widehat{I}))-w_{R}\left(I_{R}\right)
$$

Absent the retailer's short-term market concerns, the retailer's expected payoff equals the sum of the expected net cashflows.

The supplier is privately-owned and does not face pressure from the capital market. Given (1), the supplier's expected total payoff, $E\left[U_{S}\right]$, is the sum of the expected net cashflows of the two periods, i.e.,

$$
\begin{aligned}
E\left[U_{S}\right] & =E\left[\widetilde{x}_{2 S}\right]+E\left[\widetilde{x}_{1 S}\right]-w_{S}\left(I_{S}\right) \\
& =2 \mu_{S}+(1-\gamma) M(I)-w_{S}\left(I_{S}\right) .
\end{aligned}
$$

\section{Analysis}

In this section, we examine the impact of the retailer's market concerns on the decisions of both firms, as well as the implications for the whole supply chain. We are interested in how the market concerns affect the investment levels and the shares of surplus that firms obtain through the negotiation, and additionally, whether the retailer's market concerns are beneficial or detrimental for the firms and for the whole supply chain. 


\subsection{Bargaining and investments}

We examine the firms' decisions using backward induction. At date 2, the retailer and supplier negotiate about the share that each firm receives from the joint surplus that the supply chain generates. At this date, the investments have already been made and the investment costs of both firms are sunk. When trade between the two firms takes place, the retailer's expected total payoff equals

$$
E\left[U_{R}\right]=2 \mu_{R}+\gamma M(I)+\alpha_{R} \beta_{R}(\gamma M(I)-\widehat{\gamma} M(\widehat{I}))
$$

from (6). If the firms do not trade, the retailer's expected total payoff equals

$$
E\left[U_{R}\right]=2 \mu_{R}
$$

The retailer's expected net payoff from the collaboration equals $\gamma M(I)+\alpha_{R} \beta_{R}(\gamma M(I)-$ $\widehat{\gamma} M(\widehat{I}))$ and depends on the (conjectured) total trading surplus, the (conjectured) share received, and the degree of its market concerns. The supplier's expected net payoff from the collaboration equals the amount of supply chain surplus that it receives, i.e., $(1-\gamma) M(I)$ from (7).

The two firms then proceed to negotiate about the shares of surplus that each firm receives from the trade, à la generalized Nash bargaining, i.e.,

$$
\max _{\gamma}\left[\gamma M(I)+\alpha_{R} \beta_{R}(\gamma M(I)-\widehat{\gamma} M(\widehat{I}))\right]^{b}[(1-\gamma) M(I)]^{1-b}
$$

where $b \in[0,1]$ reflects the retailer's bargaining power and $(1-b)$ reflects the supplier's bargaining power. The retailer's bargaining power vis-à-vis the supplier depend on exogenous factors such as its firm size, its market power in the final product market, and how easy it is to switch to a different supplier. If not stated otherwise, we assume $b \in(0,1)$ to rule out 
corner solutions. ${ }^{7}$

Solving the bargaining problem in (10) shows that the retailer receives a share of surplus

$$
\gamma=b+\alpha_{R} \beta_{R} \widehat{\gamma} \frac{1-b}{1+\alpha_{R} \beta_{R}} \frac{M(\widehat{I})}{M(I)}
$$

Absent market concerns, the retailer's share of surplus equals its bargaining power, i.e., $\gamma=b$ if $\alpha_{R}=0$. This result is a standard finding in the hold-up literature. In the presence of market concerns, the retailer bargains more aggressively and obtains an additional markup. Intuitively, the retailer's market concerns scale its net benefit from trade to $\left(1+\alpha_{R} \beta_{R}\right) \gamma M(I)$ in the negotiation process, as shown in (10), while the supplier's interest remains at the same level at $(1-\gamma) M(I)$. Consequently, the increase of the retailer's stake in the collaboration above its bargaining power results in it bargaining more aggressively.

The capital market anticipates the power dynamics between the two firms and conjectures correctly that $\widehat{I}=I$ and $\widehat{\gamma}=\gamma$. Lemma 1 establishes the retailer's equilibrium share of surplus.

Lemma 1 In equilibrium, the retailer's share of the trading surplus is

$$
\gamma=b \frac{1+\alpha_{R} \beta_{R}}{1+b \alpha_{R} \beta_{R}}
$$

Lemma 1 shows that the presence of the retailer's market concerns amplify the retailer's bargaining power and help it obtain a higher share of surplus during the negotiation. In particular, Lemma 1 implies that the retailer's share of surplus equals its bargaining power if the retailer has (1) zero bargaining power, (2) full bargaining power, or (3) no market concerns, i.e., $\gamma=b$ if $b \in\{0,1\}$ or $\alpha_{R}=0$. Otherwise, the retailer's share increases in its

\footnotetext{
${ }^{7}$ We do not explicitly examine the trading quantity in this model since under a two part tariff the firms would always agree to set the quantity at the first-best level.
} 
degree of market concerns, i.e.,

$$
\frac{\partial \gamma}{\partial \alpha_{R}}=\frac{b(1-b) \beta_{R}}{\left(1+b \alpha_{R} \beta_{R}\right)^{2}}>0
$$

Next, we examine the firms' investment decisions. Each firm chooses an investment level that maximizes its total payoff, anticipating the equilibrium $\gamma$ from Lemma 1. Their objective functions are as follows.

$$
\begin{array}{ll}
\max _{I_{R}} & 2 \mu_{R}+\gamma M(I)+\alpha_{R} \beta_{R}(\gamma M(I)-\widehat{\gamma} M(\widehat{I}))-w_{R}\left(I_{R}\right) \\
\max _{I_{S}} & 2 \mu_{S}+(1-\gamma) M(I)-w_{S}\left(I_{S}\right) .
\end{array}
$$

The retailer's and supplier's investment decision are given by the first-order conditions:

$$
\begin{aligned}
\gamma \frac{\partial M(I)}{\partial I_{R}}+\alpha_{R} \beta_{R} \gamma \frac{\partial M(I)}{\partial I_{R}} & =w_{R}^{\prime}\left(I_{R}\right) \\
(1-\gamma) \frac{\partial M(I)}{\partial I_{S}} & =w_{S}^{\prime}\left(I_{S}\right) .
\end{aligned}
$$

For both firms, marginal investment costs (i.e., RHS) equal marginal benefits of the investments (i.e., LHS). Without the short-term market concerns, the marginal benefit of the retailer's investment equals the retailer's share of the supply chain's marginal trading surplus. Consistent with prior literature on signal jamming, the additional term, $\alpha_{R} \beta_{R} \gamma \frac{\partial M}{\partial I_{R}}$, reflects the retailer's incentive to inflate its market price by increasing its investment. The supplier does not have any market concerns and equates marginal benefits with its share of the supply chain's marginal trading surplus. The investment incentives of both firms are linked through the jointly generated profit margin, $M(I)$, that exhibits a positive complementarity between the two investments.

Given the retailer's market concerns, Proposition 1 presents the equilibrium investments made by the retailer and the supplier. 
Proposition 1 For a given $\alpha_{R}$, in equilibrium, the investments made by the retailer and supplier are

$$
\begin{aligned}
& I_{R}=\left(\left(1+\alpha_{R} \beta_{R}\right) \gamma r\right)^{\frac{1-s}{1-r-s}}((1-\gamma) s)^{\frac{s}{1-r-s}} \\
& I_{S}=\left(\left(1+\alpha_{R} \beta_{R}\right) \gamma r\right)^{\frac{r}{1-r-s}}((1-\gamma) s)^{\frac{1-r}{1-r-s}}
\end{aligned}
$$

The firms' equilbrium investments depend on the relative importance of these investments, the bargaining power of the individual firms, and the retailer's degree of market concerns. As outlined in Lemma 1, the retailer's market concerns make it a more aggressive bargainer while negotiating with the supplier about the division of the supply chain surplus. One might thus conjecture that the retailer's investment would increase in its market concerns, whereas the supplier's investment decreases. Our analysis shows that this conjecture is only true when the complementarity between the two investments is low. When the complementarity between the two investments is high, a spillover effect is generated between the two investments. As a result, both investments increase in $\alpha_{R}$ if the retailer's investment is important, and both investments decrease in $\alpha_{R}$ if the supplier's investment is important. Intuitively, if the retailer's investment is sufficiently important and the retailer invests more, the increase in the supplier's marginal benefit from the increased trading surplus offsets the lower share of surplus the supplier receives. Similarly, if the supplier's investment is sufficiently important and the supplier invests less, the retailer's marginal benefit decreases so severely that even a higher share of surplus cannot offset the effect.

For the sake of convenience, we state the marginal investments in terms of the retailer's share and the investments from Lemma 1 and Proposition 1, i.e.,

$$
\begin{aligned}
\frac{\partial I_{R}}{\partial \alpha_{R}} & =\frac{2-\gamma-2 s}{(1-r-s)\left(1+\alpha_{R} \beta_{R}\right)} \beta_{R} I_{R} \\
\frac{\partial I_{S}}{\partial \alpha_{R}} & =\frac{2 r-\gamma}{(1-r-s)\left(1+\alpha_{R} \beta_{R}\right)} \beta_{R} I_{S} .
\end{aligned}
$$

Equation (16) confirms our intuition that we summarize in Corollary 1. 
Corollary 1 (i) The investments of the retailer and the supplier both increase in the retailer's market concerns when the impact of the retailer's investment is sufficiently high and the impact of the supplier's investment is sufficiently low, i.e.,

$$
\frac{\partial I_{R}}{\partial \alpha_{R}} \geq 0 \quad \text { iff } \quad s \leq 1-\frac{\gamma}{2} \quad \text { and } \quad \frac{\partial I_{S}}{\partial \alpha_{R}} \geq 0 \quad \text { iff } \quad r \geq \frac{\gamma}{2}
$$

(ii) The retailer's investments increase and the supplier's investments decrease in the retailer's market concerns when the impact of the retailer's investment and of the supplier's investment are both sufficiently low, i.e.,

$$
\frac{\partial I_{R}}{\partial \alpha_{R}} \geq 0 \quad \text { iff } \quad s \leq 1-\frac{\gamma}{2} \quad \text { and } \quad \frac{\partial I_{S}}{\partial \alpha_{R}} \leq 0 \quad \text { iff } \quad r \leq \frac{\gamma}{2}
$$

(iii) Otherwise the retailer's and the supplier's investments both decrease in the retailer's market concerns, i.e.,

$$
\frac{\partial I_{R}}{\partial \alpha_{R}} \leq 0 \quad \text { iff } \quad s \geq 1-\frac{\gamma}{2} \quad \text { and } \quad \frac{\partial I_{S}}{\partial \alpha_{R}} \leq 0 \quad \text { iff } \quad r \leq \frac{\gamma}{2}
$$

Corollary 1 shows that the retailer's market concerns can lead to higher or lower firm investments, depending on the relative importance of the two firms' inputs in the joint production process. Figure 2 illustrates the three cases outlined in Corollary 1 by numerically illustrating the impact of the retailer's market concerns on the firms' investment decisions.

Figure 2. Impact of retailer's market concerns on investments.

Parameters are $\left(r, s, b, \beta_{R}\right)=\left(\frac{6}{10}, \frac{3}{10}, \frac{1}{2}, \frac{1}{2}\right),\left(\frac{1}{10}, \frac{1}{10}, \frac{1}{2}, \frac{1}{2}\right),\left(\frac{1}{10}, \frac{8}{10}, \frac{1}{2}, \frac{1}{2}\right)$ for Panels A, B, C. 
Solid line-retailer's investment; dashed line-supplier's investment



A

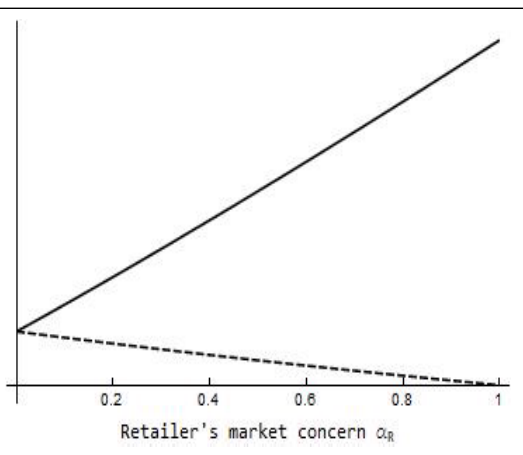

$\mathrm{B}$

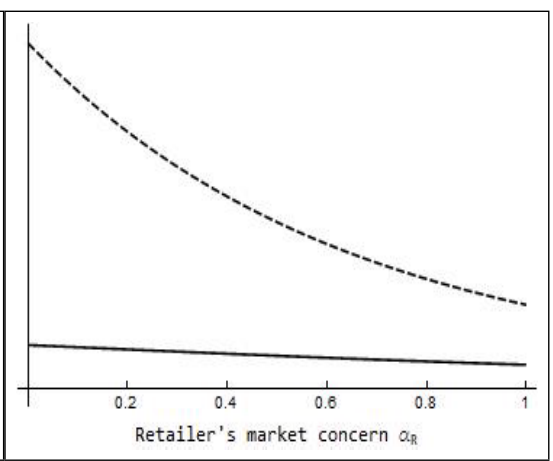

$\mathrm{C}$

\subsection{The impact of market concerns on the retailer}

In this section, we examine how the retailer's market concerns affect its firm value. The retailer's expected total payoff from (6) is $V_{R}\left(\alpha_{R}\right)=2 \mu_{R}+\gamma\left(\alpha_{R}\right) M\left(I\left(\alpha_{R}\right)\right)-w_{R}\left(I_{R}\left(\alpha_{R}\right)\right)$, where the expectation is taken ex ante before the investments are made. The retailer's market concerns affect $V_{R}$ through its effects on the investments of both firms and the retailer's share of the joint surplus. The marginal firm value reflects the impact of these three forces and equals:

$$
\frac{d V_{R}}{d \alpha_{R}}=-\alpha_{R} \beta_{R} \gamma \frac{\partial M}{\partial I_{R}} \frac{\partial I_{R}}{\partial \alpha_{R}}+\frac{\partial \gamma}{\partial \alpha_{R}} M+\gamma \frac{\partial M}{\partial I_{S}} \frac{\partial I_{S}}{\partial \alpha_{R}}
$$

The first term captures the effect of the retailer's market concerns on its firm value via its investment. As the retailer with market concerns overinvests to manage market expectations, this term has a negative sign when the retailer's investment increases in $\alpha_{R}$. This insight is consistent with Stein (1989) that myopic behavior induces value destroying investment incentives. While the effect of market concerns in Stein (1989) is always one sided, in our model the retailer's investment could increase or decrease in $\alpha_{R}$. That is, the first term of equation (17) is negative if $\frac{\partial I_{R}}{\partial \alpha_{R}} \geq 0$ (and vice versa). The second term shows that higher market concerns results in higher share of the supply chain surplus for the retailer, which has a positive effect on the firm value, i.e., $\frac{\partial \gamma}{\partial \alpha_{R}} M \geq 0$. The last term reflects the effect of the retailer's market concerns on the firm value via the supplier's investments. This term has 
either a positive or a negative value depending on whether the supplier's investment increase or decrease in $\alpha_{R}$, i.e., $\gamma \frac{\partial M}{\partial I_{S}} \frac{\partial I_{S}}{\partial \alpha_{R}} \geq 0$ if $\frac{\partial I_{S}}{\partial \alpha_{R}} \geq 0$ (and vice versa).

We provide further insights by restating the marginal firm value (17) in two steps. In a first step, we exploit the familiar relation for the Cobb-Douglas profit margin, $\frac{\partial M}{\partial I_{R}}=\frac{r M}{I_{R}}$ and $\frac{\partial M}{\partial I_{S}}=\frac{s M}{I_{S}}$. In a second step, we substitute the retailer's share of surplus from Lemma 1 and the marginal investments from (16). That is,

$$
\begin{aligned}
\frac{d V_{R}}{d \alpha_{R}} & =\left(-\alpha_{R} \beta \beta_{R} \gamma \frac{r}{I_{R}} \frac{\partial I_{R}}{\partial \alpha_{R}}+\frac{\partial \gamma}{\partial \alpha_{R}}+\gamma \frac{s}{I_{S}} \frac{\partial I_{S}}{\partial \alpha_{R}}\right) M \\
& =\left(k_{0}+k_{1} \alpha_{R}+k_{2} \alpha_{R}^{2}\right) \frac{b \beta_{R} M}{(1-r-s)\left(1+b \beta_{R} \alpha_{R}\right)^{2}},
\end{aligned}
$$

with the coefficients, $k_{0}=(1-b)(1-r)-s(1-2 r), k_{1}=-(2 r(1-b s-s)-b(r-s)) \beta_{R}<0$, and $k_{2}=r(2 s-1) b \beta_{R}^{2}$. The sign of (18) is determined by the sign of the quadratic function, $k_{0}+k_{1} \alpha_{R}+k_{2} \alpha_{R}^{2}$

The proof of Proposition 2 will show that the retailer's firm value decreases in its market concerns when the intercept of the quadratic function has a positive value, i.e., $\frac{d V_{R}}{d \alpha_{R}}<0$ if $k_{0}<0$. That is, in line with prior results, the retailer's market concern is detrimental for it. If $k_{0}>0$, then the retailer's market concern can be beneficial for it. The retailer's firm value increases in its market concerns for $\alpha_{R} \leq \bar{\alpha}_{R}$ and decreases in the retailer's market concerns for $\alpha_{R} \geq \bar{\alpha}_{R}$, where $\bar{\alpha}_{R}$ is the unique level that maximizes the firm value. The sign of $k_{0}$ can be expressed in terms of the importance of the retailer's and supplier's investment.

Proposition 2 summarizes our finding.

Proposition 2 (i) When the retailer's investment is sufficiently important relative to the supplier's investment, a unique level of retailer myopic market concerns, denoted as $\bar{\alpha}_{R}$, exists that maximizes the firm value of the retailer. That is, $\bar{\alpha}_{R}=($ A 7$)$ when either (a) $r<\frac{1}{2}$ and $s<\frac{(1-b)(1-r)}{1-2 r}$ or $(b) r \geq \frac{1}{2}$.

(ii) When the supplier's investment is sufficiently important relative to the retailer's investment, then the firm value of the retailer decreases in the retailer's myopic market concerns. 
That is, $\bar{\alpha}_{R}=0$ when $r<\frac{1}{2}$ and $s>\frac{(1-b)(1-r)}{1-2 r}$.

Figure 3. Impact of retailer's market concerns on its firm value.

Parameters are $\left(r, s, b, \beta_{R}\right)=\left(\frac{6}{10}, \frac{3}{10}, \frac{1}{2}, \frac{1}{2}\right),\left(\frac{1}{10}, \frac{1}{10}, \frac{1}{2}, \frac{1}{2}\right),\left(\frac{1}{10}, \frac{8}{10}, \frac{1}{2}, \frac{1}{2}\right)$ for Panels A, B, C.



A

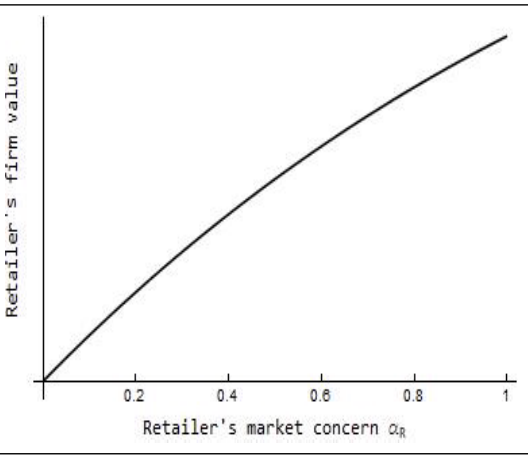

$\mathrm{B}$

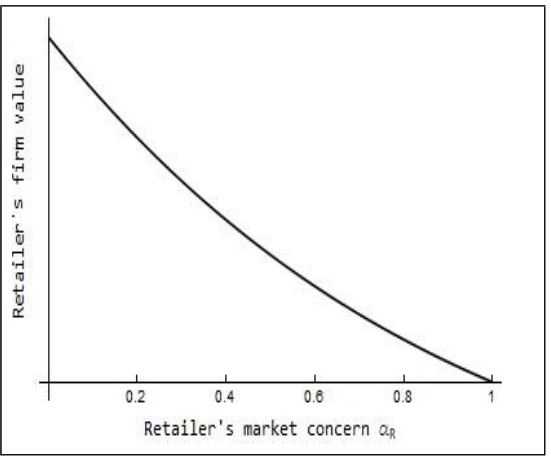

C

Figure 3 illustrates the impact of the retailer's market concerns on the retailer's firm value, where we use the same parameters as in Figure 2. Panels A and B of Figures 3 show that the retailer's firm value increases in its market concerns while the firm value unambiguously decreases in $\alpha_{R}$ in Panel C.

\section{One-sided investment}

To provide further insights into how our supply chain model is related to the single-firm case, we consider the special case that only the retailer's investment is necessary for the joint supply chain collaboration, i.e., $s=0 .{ }^{8}$ In this case, the retailer's investment equals $I_{R}=\left(\left(1+\alpha_{R} \beta_{R}\right) \gamma r\right)^{\frac{1}{1-r}}$ and unambiguously increases in $\alpha_{R}$. The retailer's market concerns have a negative impact on its firm value due to overinvestment, but has a positive impact as the retailer receives a higher share of surplus. The marginal firm value captures these two forces as follows:

$$
\frac{d V_{R}}{d \alpha_{R}}=-\alpha_{R} \beta_{R} \gamma \frac{\partial M}{\partial I_{R}} \frac{\partial I_{R}}{\partial \alpha_{R}}+\frac{\partial \gamma}{\partial \alpha_{R}} M
$$

The positive impact dominates for $\alpha_{R}=0$. The level of market concerns that maximizes

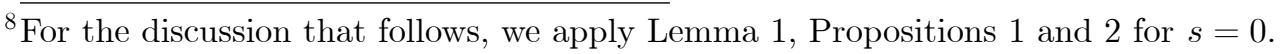


the retailer's firm value is

$$
\bar{\alpha}_{R}=\frac{\sqrt{4 b(1-b)+r\left(4+5 b^{2}-8 b\right)}-(2-b) \sqrt{r}}{2 b \sqrt{r} \beta_{R}} .
$$

The retailer's market value decreases in its bargaining power as the positive impact of $\alpha_{R}$ on the its share of surplus diminishes in $b$, i.e., $\frac{\partial \bar{\alpha}_{R}}{\partial b}<0$. If the retailer is the residual claimant of the supply chain surplus, then the positive impact of $\alpha_{R}$ on the retailer's share goes down to zero. In this case, consistent with the single firm scenario in Stein (1989), the market concerns are unambiguously detrimental for the retailer as it induces inefficient investments, i.e., (20) implies $\bar{\alpha}_{R}=0$ for $b=1$.

\subsection{The impact of market concerns on the whole supply chain}

From the perspective of the integrated system (i.e., the whole supply chain), a hold-up problem arises when each firm has to bear the full cost of the investment, but does not receive its full benefits. Corollary 1 shows that the myopic market concerns of the retailer can increase or reduce the investments of the firms. When the retailer's investment is more important than the supplier's investment for the collaboration, its market concerns can mitigate the hold-up problem and increase supply chain efficiency. When the supplier's investment is more important than the retailer's investment, the retailer's market concerns would instead exacerbate the hold-up problem and further reduce the supply chain efficiency.

To elaborate, the value of the whole supply chain equals the expected ex ante total payoff, $V_{T}=2 \mu_{R}+2 \mu_{S}+M(I)-w_{R}\left(I_{R}\right)-w_{S}\left(I_{S}\right)$, and the resulting first-best investments, $I^{*}=\left(I_{R}^{*}, I_{S}^{*}\right)$, maximize the value of the whole supply chain and satisfy the following standard first-order conditions:

$$
\frac{\partial M\left(I^{*}\right)}{\partial I_{R}}=w_{R}^{\prime}\left(I_{R}^{*}\right) \text { and } \frac{\partial M\left(I^{*}\right)}{\partial I_{S}}=w_{S}^{\prime}\left(I_{S}^{*}\right)
$$

That is, the marginal benefits from the investments equal the marginal investment costs. 
Without the retailer's market concerns, the first-order conditions of the firms' investment decisions in (15) show that a standard hold-up problem arises as each firm receives only a fraction of the marginal benefits from its investments. The firms thus invest below the efficient level from the perspective of the whole supply chain. Corollary 1 (i) shows that the retailer's market concerns can increase the investments of both firms. The associated first-order conditions (15) imply that the first-best investments, $I^{*}$, can only be induced if each firm receives hundred percent of the marginal benefits from its investments, i.e., if $\gamma+\alpha_{R} \beta_{R} \gamma=1$ and $(1-\gamma)=1$. The two equations cannot be satisfied simultaneously and total supply chain efficiency cannot be induced by $\alpha_{R}$ alone. Corollary 2 summarizes our result.

Corollary 2 In case of bilateral investments, it is impossible that retailer and supplier both invest efficiently from the perspective of the whole supply chain.

To explore this issue in more detail, we consider the impact of the retailer's market concerns on the marginal value of the whole supply chain in two steps. In the first step, we account for the investment decisions of the two firms in (15). In the second step, we exploit the familiar relation for the Cobb-Douglas profit margin, $\frac{\partial M}{\partial I_{R}}=\frac{r M}{I_{R}}$ and $\frac{\partial M}{\partial I_{S}}=\frac{s M}{I_{S}}$, and account for the retailer's share in Lemma 1 and the marginal investments from (16). That is,

$$
\begin{aligned}
\frac{d V_{T}}{d \alpha_{R}} & =\left(1-\gamma-\alpha_{R} \beta_{R} \gamma\right) \frac{\partial M}{\partial I_{R}} \frac{\partial I_{R}}{\partial \alpha_{R}}+\gamma \frac{\partial M}{\partial I_{S}} \frac{\partial I_{S}}{\partial \alpha_{R}} \\
& =\left(c_{0}+c_{1} \alpha_{R}+c_{2} \alpha_{R}^{2}+c_{3} \alpha_{R}^{3}\right) \frac{\beta_{R} M}{(1-r-s)\left(1+\alpha_{R} \beta_{R}\right)\left(1+b \alpha_{R} \beta_{R}\right)^{2}}
\end{aligned}
$$

with $c_{0}=(2-b)(1-b) r+r s(4 b-2)-s b^{2}$ and other coefficients of the cubic function displayed in (A8).

The proof of Proposition 3 will show that the retailer's market concerns are only detrimental for the whole supply chain if the intercept of the cubic function is negative, i.e., if $c_{0}<0$. For $c_{0}>0$, the value of the whole supply chain increases in the retailer's market 
concerns for $\alpha_{R} \leq \alpha_{R}^{T}$ and then decreases afterwards, where $\alpha_{R}^{T}$ is the level of retailer's market concerns that maximizes the value of the supply chain. The sign of $c_{0}$ can be expressed in terms of the importance of the retailer's and supplier's investment.

Proposition 3 provides details.

Proposition 3 (i) When the retailer's investment is sufficiently important relative to the supplier's investment, a unique level of retailer myopic market concerns exists that maximizes the value of the whole supply chain. That is, $\alpha_{R}^{T}=(A 10)$ when $r>\frac{b^{2}}{(1-b)(2-b)+s(4 b-2)}$ s and $s<\frac{(1-b)(2-b)}{2-4 b}$ if $b<\frac{1}{2}$.

(ii) When the supplier's investment is sufficiently important relative to the retailer's investment, the value of the whole supply chain decreases in the retailer's myopic market concerns. That is, $\alpha_{R}^{T}=0$ when $s>\frac{(2-b)(1-b)}{b^{2}+r(2-4 b)} r$ and $r<\frac{b^{2}}{4 b-2}$ if $b>\frac{1}{2}$.

Proposition 3 shows that depending on the importance of the retailer's and supplier's investment the retailer's market concerns can increase or reduce the value of the whole supply chain. Figure 4 provides a numerical illustration for the same parameters that are used in Figures 2 and 3.

Figure 4. Impact of retailer's market concerns on supply chain's payoff. Parameters are $\left(r, s, b, \beta_{R}\right)=\left(\frac{6}{10}, \frac{3}{10}, \frac{1}{2}, \frac{1}{2}\right),\left(\frac{1}{10}, \frac{1}{10}, \frac{1}{2}, \frac{1}{2}\right),\left(\frac{1}{10}, \frac{8}{10}, \frac{1}{2}, \frac{1}{2}\right)$ for Panels A, B, C.

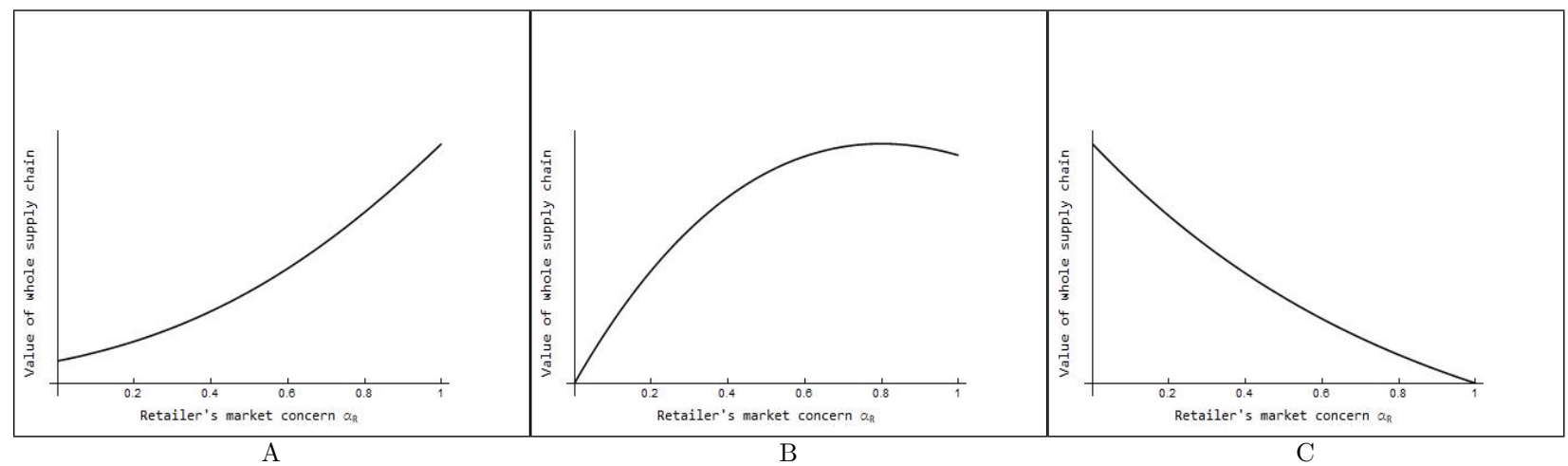

\section{One-sided investment}

In the special case of one-sided investment by the retailer only, supply chain efficiency can be fully restored through the retailer's market concerns. In this case, the marginal value 
from (22) reduces to:

$$
\frac{d V_{T}\left(\alpha_{R}\right)}{d \alpha_{R}}=\left(1-\gamma-\alpha_{R} \beta_{R} \gamma\right) \frac{\partial M\left(I_{R}\right)}{\partial I_{R}}
$$

When the effect of market concerns on the retailer's investment exactly offsets the share of surplus that the supplier receives, i.e., if $\alpha_{R}^{T} \beta_{R} \gamma=(1-\gamma)$ is satisfied, the result is equivalent to the retailer receiving $100 \%$ of the supply chain surplus. Hence, the retailer is effectively fully motivated to invest efficiently for the supply chain, and the level of market concerns that maximizes the supply chain value is

$$
\alpha_{R}^{T}=\frac{\sqrt{4 b-3 b^{2}}-b}{2 b \beta_{R}} .
$$

\subsection{The impact of market concerns on the supplier}

The retailer's market concern also affects the privately owned supplier. On one hand, the supplier is disadvantaged because the retailer becomes an aggressive bargainer, which reduces the supplier's share of surplus in the negotiation. On the other hand, the supplier also benefits from the retailer's market concerns as they may increase the retailer's investment in the supply chain. The supplier's investment itself does not play a role, as the supplier invests efficiently from its own perspective. Applying the Envelope Theorem, we show that the supplier's expected marginal payoff reflects these two forces:

$$
\frac{d V_{S}}{d \alpha_{R}}=-\frac{\partial \gamma}{\partial \alpha_{R}} M+(1-\gamma) \frac{\partial M}{\partial I_{R}} \frac{\partial I_{R}}{\partial \alpha_{R}}
$$

Since $\frac{\partial M}{\partial I_{R}}=\frac{r M}{I_{R}}$, Equation (25) can be restated as:

$$
\frac{d V_{S}}{d \alpha_{R}}=\left(2 r-b+(2 r-1) \alpha_{R} b \beta_{R}\right) \frac{\left(1-b \beta_{R}\right)(1-s) M}{(1-r)\left(1+\alpha_{R} \beta_{R}\right)\left(1+\alpha_{R} b \beta_{R}\right)^{2}}
$$

The supplier only benefits from the retailer's market concerns if the retailer's investment has 
a sufficiently large impact on the collaboration, i.e., if $r>\frac{b}{2}$. In this case, the supplier's expected payoff increases in the retailer's market concerns when $\alpha_{R} \leq \alpha_{R}^{S}$ and decreases when $\alpha_{R} \geq \alpha_{R}^{S}$, with the level of retailer market concerns maximizing the supplier payoff being $\alpha_{R}^{S}=\frac{2 r-b}{(2 r-1) b \beta_{R}}$.

\section{Observability}

In a signal jamming model, the sender is trapped in a bad equilibrium as she has to choose a distorted action. The sender would have been better off if she could commit to not distort her action or if her action can be observed by the receiver. In Stein (1989), if the capital market could perfectly observe the investments, the firm may no longer have incentives to manipulate the stock price. In this section, we discuss the implications in our model when the capital market has perfect information about the retailer's and supplier's investments and the retailer's share.

In this case of symmetric information, the market's information set is given by $Y_{+}^{m}=$ $\left\{x_{1 R}, I, \gamma\right\}$ and the market price equals $p_{R}=E\left[\widetilde{x}_{2 R} \mid Y_{+}^{m}\right]=E\left[\widetilde{x}_{2 R}\right]+\beta_{R}\left(\widetilde{\pi}_{1 R}-E\left[\widetilde{\pi}_{1 R}\right]\right)$. The law of iterated expectations applies and the expected market price equals the expected cash flow, $E\left[p_{R}\right]=E\left[\widetilde{x}_{2 R}\right]$, which removes the retailer's incentive to distort the market price. The retailer's share of surplus equals its bargaining power and both firms invest efficiently from their own perspectives. This is equivalent to the case that $\alpha_{R}=0$ with the associated payoffs for the retailer, the whole supply chain, and the supplier, $V_{R}(0), V_{T}(0)$ and $V_{S}(0)$. Propositions 2, 3, and equation (26) provide conditions under which it is benefical when the capital market does not observe the firms' decisions for the retailer, the whole supply chain, and the supplier, respectively. The interpretations follow directly from these results.

Proposition 4 It can be beneficial for the supplier, the retailer, and the whole supply chain benefit when the capital market does not observe the firms' decisions. 


\section{Both firms are publicly listed}

In this section, we discuss the case where both firms are publicly listed. For simplicity, we let the two firms be symmetric with the same bargaining power and same importance of investments, i.e., $b=\frac{1}{2}, M(I)=I_{R}^{r} I_{S}^{r}$ with $0 \leq r<\frac{1}{2}, \sigma_{i}^{2}=\sigma^{2}$ and $\rho_{i}=\rho$ for $i=R, S$. Having removed the mechanism that leads to differences in investment levels, we show that the investments of both firms increase in their market concerns. As a result, the market concerns can increase the value for both firms as well as the value of the whole supply chain.

We denote with $\gamma_{i}$ the share of surplus that firm $i$ receives and slightly extend the definition of the firm's cashflow by introducing an additional noise term that reflects correlation between the profit margin at period 1 and 2, i.e., $\widetilde{x}_{1 i}\left(\gamma_{i}, I\right)=\widetilde{\pi}_{1 i}+\gamma_{i} M(I)+\widetilde{\theta}_{1}$ and $\widetilde{x}_{2 i}=\widetilde{\pi}_{2 i}+\widetilde{\theta}_{2}$ with $\widetilde{\theta}_{t} \sim N\left(0, \sigma_{\theta}^{2}\right)$ and $\operatorname{Cov}\left[\widetilde{\theta}_{1}, \widetilde{\theta}_{2}\right]=\rho_{\theta} \geq 0$ for $i=R, S$ and $t=1,2 .^{9}$

The market price for firm $i$ reflects the market's expectation of firm $i$ 's future cashflows, $p_{i}=E\left[\widetilde{x}_{2 i} \mid Y^{m}\right]$, given the market's information $Y^{m}=\left\{x_{1 R}, x_{1 S}, \widehat{I}, \widehat{\gamma}\right\}$. The capital market prices firm $i$ by using the period-1 cashflows of both firms to update its belief:

$$
p_{i}=E\left[\widetilde{x}_{2 i}\right]+\beta\left(x_{1 i}-E\left[\widehat{x}_{1 i}\right]\right)-\delta\left(x_{1 j}-E\left[\widehat{x}_{1 j}\right]\right),
$$

where we denote the conjectured values as $\widehat{x}_{1 i}=\widetilde{x}_{1 i}\left(\widehat{\gamma}_{i}, \widehat{I}\right)$ and $\widehat{x}_{1 j}=\widetilde{x}_{1 j}\left(\widehat{\gamma}_{j}, \widehat{I}\right)$. Same as before, $\beta=\frac{\sigma_{\theta}^{2} \rho+\sigma^{2}\left(\rho_{\theta}+\rho\right)}{\sigma^{4}+2 \sigma^{2} \sigma_{\theta}^{2}}$ and $\delta=\frac{\sigma_{\theta}^{2} \rho-\sigma^{2} \rho_{\theta}}{\sigma^{4}+2 \sigma^{2} \sigma_{\theta}^{2}}$ are the weights with normally distributed random $\theta$, with $i, j=R, S$ and $i \neq j$.

Accounting for the market price (27), firm $i$ 's objective function equals

$$
E\left[U_{i}\right]=2 \mu_{i}+\gamma_{i} M(I)+\alpha_{i}\left(\left[\beta \gamma_{i}-\delta \gamma_{j}\right] M(I)-\left[\beta \widehat{\gamma}_{i}-\delta \widehat{\gamma}_{j}\right] M(\widehat{I})\right)-w_{i}\left(I_{i}\right)
$$

\footnotetext{
${ }^{9}$ Note that introducing the additional noise term does not change any of our prior insights.
} 
The two firms then bargain over their shares for the joint surplus, i.e.,

$$
\max _{\gamma} \prod_{\substack{i, j=R, S \\ i \neq j}}\left[\gamma_{i} M(I)+\alpha_{i}\left(\left[\beta \gamma_{i}-\delta \gamma_{j}\right] M(I)-\left[\beta \widehat{\gamma}_{i}-\delta \widehat{\gamma}_{j}\right] M(\widehat{I})\right)\right]^{\frac{1}{2}}
$$

In equilibrium, the conjectures of the market are correct and firm $i$ 's share of surplus equals:

$$
\gamma_{i}=\frac{1+\alpha_{i}(\beta+\delta)}{2+\left(\alpha_{R}+\alpha_{S}\right)(\beta+\delta)}
$$

Equation (30) extends our prior finding in Lemma 1. In particular, firm i's share of surplus increases in the degree of its own market concerns, $\alpha_{i}$, and decreases in the degree of firm $j$ 's market concerns, $\alpha_{j}$. If the firms have the same degree of market concerns, then each firm receives half of the surplus. Firm $i$ 's share of surplus also increases in the weight that the market assigns to the cash flow if its degree of market concerns exceeds the degree of market concerns of the other firm (and vice versa), i.e., $\operatorname{sgn}\left[\frac{\partial \gamma_{i}}{\partial \beta}\right]=\operatorname{sgn}\left[\frac{\partial \gamma_{i}}{\partial \delta}\right]=\operatorname{sgn}\left[\alpha_{i}-\alpha_{j}\right]$.

Anticipating the bargaining outcome, each firm determines its investment to maximize its expected payoff in (28), implying the following first-order condition:

$$
\gamma_{i} \frac{\partial M(I)}{\partial I_{i}}+\alpha_{i}\left[\beta \gamma_{i}-\delta \gamma_{j}\right] \frac{\partial M(I)}{\partial I_{i}}=w_{i}^{\prime}\left(I_{i}\right)
$$

That is, the marginal investment costs equal the marginal benefits accounting for the market effect. For $\alpha_{i}=0$, the marginal benefit of the investment equals firm $i$ 's share of the supply chain marginal profit. The additional term, $\alpha_{i}\left[\beta \gamma_{i}-\delta \gamma_{j}\right] \frac{\partial M(I)}{\partial I_{i}}$, reflects firm $i$ 's incentives to inflate its market price by adjusting its investment. Firm $i$ 's incentives increase in its share and in the weight that the market assigns to its cash flow, $\beta$, and decreases in firm $j$ 's share and the weight that the market assigns to firm $j$ 's cash flow, $\delta$. In equilibrium, the market's conjectures are correct and firm $i$ 's investments are given by:

$$
I_{i}=\left(\left(\gamma_{i}+\alpha_{i}\left[\beta \gamma_{i}-\delta \gamma_{j}\right]\right) r\right)^{\frac{1-r}{1-2 r}}\left(\left(\gamma_{j}+\alpha_{j}\left[\beta \gamma_{j}-\delta \gamma_{i}\right]\right) r\right)^{\frac{r}{1-2 r}}
$$


Next, we examine the marginal impact of myopic market concerns on the firm value, i.e., $V_{i}(\alpha)=2 \mu_{i}+\gamma_{i}(\alpha) M(I(\alpha))-w_{i}\left(I_{i}(\alpha)\right)$ and $\alpha=\left(\alpha_{R}, \alpha_{S}\right)$. In line with (17), the marginal expected payoff of firm $i$ consists of three terms that reflect the impact of $\alpha_{i}$ on firm $i$ 's share of surplus and the two investments. The effects of $\alpha_{i}$ on firm $i$ 's share of surplus and firm $j$ 's investment determine whether the market concerns are beneficial for firm $i$ or not. In our symmetric set-up both firms exhibit the same level of market concerns and thus both investments increase in $\alpha$. In particular, the proof of Proposition 5 shows that the marginal expected payoff of firm $i$ is proportional to a quadratic function, i.e., $d_{0}+d_{1} \alpha_{i}+d_{2} \alpha_{i}^{2}$ with coefficients, $d_{0}=(1-3 r)(\beta+\delta)+4 r^{2} \beta, d_{1}=((1-4 r) \beta+\delta)((1-2 r) \beta-\delta)$, and $d_{2}=-r((3-4 r) \beta-\delta)\left(\beta^{2}-\delta^{2}\right)$ for $i=R, S$.

Proposition 5 summarizes the result.

Proposition 5 For the case of symmetric firms, there is a unique positive level of myopic market concerns that maximizes the firm value of $i$, i.e., $\bar{\alpha}_{i}=\min \left\{\frac{d_{1}+\sqrt{d_{1}^{2}+4 d_{0} d_{2}}}{2 d_{2}}, 1\right\}$.

Finally, we consider the whole supply chain and the associated value equals: $V_{T}(\alpha)=$ $2 \mu_{R}+2 \mu_{S}+M(I(\alpha))-w_{i}\left(I_{i}(\alpha)\right)-w_{j}\left(I_{j}(\alpha)\right)$. Accounting for firm $i$ 's investment decision in (32) and the resulting equilibrium value, $\gamma_{i}=\frac{1}{2}$, the expected marginal payoff equals

$$
\frac{d V_{T}}{d \alpha_{i}}=\sum_{i=R}^{S} \frac{1-\alpha_{i}(\beta-\delta)}{2} \frac{\partial M}{\partial I_{i}} \frac{\partial I_{i}}{\partial \alpha_{i}}
$$

and can be interpreted in line with (22). Equation (33) implies that the value of the whole supply chain increases in $\alpha_{i}$ and is maximized for $\alpha_{i}=\alpha_{j}=1$. First-best supply chain efficiency, however, is not achievable as this requires $\alpha_{i}=\alpha_{j}=\frac{1}{\beta-\delta}>1$.

Corollary 3 For the case of symmetric firms, the value of the whole supply chain increases in the myopic market concerns. First-best supply chain efficiency cannot be achieved. 


\section{Conclusion}

We investigate the impact of a publicly-traded firm's myopic market concerns on the investment decisions of itself and its privately-owned supply chain partner. While the market concerns help the public firm in obtaining a higher share of the joint supply chain surplus through bargaining, its effect on the total size of the joint surplus can be positive or negative. When the public firm's investment is sufficiently more important than the private firm's investment, market concerns lead to higher investments and thus higher joint surplus. When the private firm's investment is more important, the opposite is true. Accordingly, a firm's myopic market concerns can be beneficial or detrimental for itself as well as the whole supply chain.

Our results have interesting practical implications. While conventional wisdom may predict that supply chain partners' concerns for their stock prices can mitigate hold-up problems and brings forth efficiency improvement, we show this is not always the case. If the firm with the market concerns is responsible for making the critical contribution for the supply chain performance, all incentives are aligned and Pareto improvements can be achieved. However, if the supply chain collaboration depends more heavily on the private firm, the aggressive bargaining of the publicly-traded partner disincentivizes its private partner firm and results in decreased investments from both sides.

\section{Appendix. Proofs}

Proof of Lemma 1 We consider the bargaining problem in (10). For simplicity, we abbreviate the conjectured profit margin $M(\widehat{I})$ as $\widehat{M}$. The first-order condition with respect to $\gamma$ 
is

$$
\begin{aligned}
& b\left(1+\alpha_{R} \beta_{R}\right) M\left[\gamma M+\alpha_{R} \beta_{R}(\gamma M-\widehat{\gamma} \widehat{M})\right]^{b-1}[(1-\gamma) M]^{1-b} \\
& -(1-b) M\left[\gamma M+\alpha_{R} \beta_{R}(\gamma M-\widehat{\gamma} \widehat{M})\right]^{b}[(1-\gamma) M]^{-b} \\
= & M\left[\gamma M+\alpha_{R} \beta_{R}(\gamma M-\widehat{\gamma} \widehat{M})\right]^{b-1}[(1-\gamma) M]^{-b} \\
& \cdot\left[b\left(1+\alpha_{R} \beta_{R}\right)(1-\gamma) M-(1-b)\left(\gamma M+\alpha_{R} \beta_{R}(\gamma M-\widehat{\gamma} \widehat{M})\right)\right],
\end{aligned}
$$

which implies (11). The second-order condition is given by

$$
-M^{2}\left[1+\alpha_{R} \beta_{R}\right]\left[b\left(\gamma M+\alpha_{R} \beta_{R}(\gamma M-\widehat{\gamma} \widehat{M})\right)\right]^{-(1-b)}\left[(1-b)\left(M-\frac{\alpha_{R} \beta_{R} \widehat{\gamma} \widehat{M}}{1+\alpha_{R} \beta_{R}}\right)\right] .
$$

In equilibrium, the conjectures are always correct, thus $\widehat{\gamma}=\gamma$ and $\widehat{M}=M$. We obtain the equilibrium value $\gamma$ from Lemma 1, and the second-order condition (A2) is fulfilled with

$$
-\frac{\left(1+b \alpha_{R} \beta_{R}\right)}{b}[M]^{-b}\left[\frac{b\left(1+\alpha_{R} \beta_{R}\right) M}{1+b \alpha_{R} \beta_{R}}\right]^{b}\left[\frac{(1-b) M}{1+b \alpha_{R} \beta_{R}}\right] \leq 0
$$

Proof of Proposition 1 follows from solving the first-order conditions in (15). For $i=R, S$, the associated second-order condition is satisfied as $\frac{\partial^{2} M}{\partial^{2} I_{i}}<0$.

Proof of Corollary 1 Given the investments from Proposition 1, the marginal investments of the retailer and the supplier are

$$
\begin{aligned}
\frac{d I_{R}}{d \alpha_{R}} & =\frac{1-b+\left(1+b \alpha_{R} \beta_{R}\right)(1-2 s)}{(1-r-s)\left(1+\alpha_{R} \beta_{R}\right)\left(1+b \alpha_{R} \beta_{R}\right)} \beta_{R} I_{R} \\
& =\frac{2+\gamma-2 s}{(1-r-s)\left(1+\alpha_{R} \beta_{R}\right)} \beta_{R} I_{R}
\end{aligned}
$$


and

$$
\begin{aligned}
\frac{d I_{S}}{d \alpha_{R}} & =\frac{2 r\left(1+b \alpha_{R} \beta_{R}\right)-b\left(1+\alpha_{R} \beta_{R}\right)}{(1-r-s)\left(1+\alpha_{R} \beta_{R}\right)\left(1+b \alpha_{R} \beta_{R}\right)} \beta_{R} I_{S} \\
& =\frac{2 r-\gamma}{(1-r-s)\left(1+\alpha_{R} \beta_{R}\right)} \beta_{R} I_{S},
\end{aligned}
$$

where we insert the equilibrium value $\gamma$ from Lemma 1. Points (i), (ii), and (iii) follow from $\operatorname{sgn}\left[\frac{d I_{R}}{d \alpha_{R}}\right]=\operatorname{sgn}[2+\gamma-2 s]$ and $\operatorname{sgn}\left[\frac{d I_{S}}{d \alpha_{R}}\right]=\operatorname{sgn}[2 r-\gamma]$. As $s>1-\frac{\gamma}{2}$ holds true in conjunction with the regularity condition, $1>r+s$, we know $r<\frac{\gamma}{2}$.

Proof of Proposition 2 We use $\frac{\partial M}{\partial I_{R}}=\frac{r M}{I_{R}}$ and $\frac{\partial M}{\partial I_{S}}=\frac{s M}{I_{S}}$, Equation (13), and Lemma 1 to restate the marginal value from (17) as

$$
\begin{aligned}
\frac{d V_{R}}{d \alpha_{R}} & =\left(\gamma \frac{\partial M}{\partial I_{R}}-w_{R}^{\prime}\right) \frac{\partial I_{R}}{\partial \alpha_{R}}+\frac{\partial \gamma}{\partial \alpha_{R}} M+\gamma \frac{\partial M}{\partial I_{S}} \frac{\partial I_{S}}{\partial \alpha_{R}} \\
& =-\alpha_{R} \beta_{R} \gamma \frac{\partial M}{\partial I_{R}} \frac{\partial I_{R}}{\partial \alpha_{R}}+\frac{\partial \gamma}{\partial \alpha_{R}} M+\gamma \frac{\partial M}{\partial I_{S}} \frac{\partial I_{S}}{\partial \alpha_{R}} \\
& =\left(-\alpha_{R} \beta_{R} \gamma \frac{r}{I_{R}} \frac{\partial I_{R}}{\partial \alpha_{R}}+\frac{\partial \gamma}{\partial \alpha_{R}}+\gamma \frac{s}{I_{S}} \frac{\partial I_{S}}{\partial \alpha_{R}}\right) M \\
& =\left(k_{0}+k_{1} \alpha_{R}+k_{2} \alpha_{R}^{2}\right) \frac{b \beta_{R} M}{(1-r-s)\left(1+b \beta_{R} \alpha_{R}\right)^{2}},
\end{aligned}
$$

with $k_{0}=(1-b)(1-r)-s(1-2 r), k_{1}=-(2 r(1-b s-s)-b(r-s)) \beta_{R}<0$, and $k_{2}=r(2 s-1) b \beta_{R}^{2}$.

(i) Assume a positive intercept, $k_{0}>0$, and denote the two potential zeros of the quadratic function with $z_{1}=\frac{-k_{1}-\sqrt{k_{1}^{2}-4 k_{0} k_{2}}}{2 k_{2}}$ and $z_{2}=\frac{-k_{1}+\sqrt{k_{1}^{2}-4 k_{0} k_{2}}}{2 k_{2}}$. Three cases emerge: (a) If the quadratic function has a $\mathrm{u}$-shape, $k_{2}>0$, then the function has a negative value of $k_{0}-\frac{k_{1}^{2}}{4 k_{2}}<0$ at the vertex, $-\frac{k_{1}}{2 k_{2}}>0$. This implies that the quadratic function has two different zeros, i.e., $\sqrt{k_{1}^{2}-4 k_{0} k_{2}}>0$. Since the quadratic function decreases at the intercept, $\left.\frac{\partial\left(k_{0}+k_{1} \alpha_{R}+k_{2} \alpha_{R}^{2}\right)}{\partial \alpha_{R}}\right|_{\alpha_{R=0}}=k_{1}<0$, we know that $\bar{\alpha}_{R}$ equals the smaller root, $\bar{\alpha}_{R}=z_{1}$. In fact, we can show the larger root is not within the interval $[0,1]$. To do so, we assume $z_{2}=\frac{-k_{1}-\sqrt{k_{1}^{2}-4 k_{0} k_{2}}}{2 k_{2}} \leq 1$, which implies $-\sqrt{k_{1}^{2}-4 k_{0} k_{2}} \leq\left(2 k_{2}+k_{1}\right)$. This constitutes a contradiction as $z_{1}=\frac{-k_{1}+\sqrt{k_{1}^{2}-4 k_{0} k_{2}}}{2 k_{2}} \leq 1$ implies $\sqrt{k_{1}^{2}-4 k_{0} k_{2}} \leq\left(2 k_{2}+k\right)$. (b) If the 
quadratic function has an inverted u-shape, $k_{2}<0$, then $\bar{\alpha}_{R}$ equals the larger root, $\bar{\alpha}_{R}=z_{1} \cdot{ }^{10}$ (c) If the quadratic function collapses to a linear function, $k_{2}=0$, then we get $\bar{\alpha}_{R}=-\frac{k_{0}}{k_{1}} \geq 0$ as $k_{1} \leq 0$. Further, $k_{2}=0$ is true if and only if $s=\frac{1}{2}$.

For the sake of convenience, we summarize the optimal value in terms of the coefficients of the quadratic function as follows:

$$
\bar{\alpha}_{R}=\left\{\begin{array}{cc}
\min \left\{\frac{-k_{1}-\sqrt{k_{1}^{2}-4 k_{0} k_{2}}}{2 k_{2}}, 1\right\} & \text { if } s \neq \frac{1}{2} \\
\min \left\{-\frac{k_{0}}{k_{1}}, 1\right\} & \text { if } s=\frac{1}{2},
\end{array}\right.
$$

with $\alpha_{R} \in[0,1]$.

(ii) Assume a negative intercept, $k_{0}<0$, then three cases emerge: (a) If the quadratic function collapses to a linear function, $k_{2}=0$, then $k_{0}+k_{1} \alpha_{R} \leq 0$ for all $\alpha_{R}$ since $k_{1} \leq 0$. (b) If the quadratic function has an inverted u-shape, $k_{2}<0$, then the quadratic function has a negative value at $\alpha_{R}=0$ and decreases as $\frac{\partial\left(k_{0}+k_{1} \alpha_{R}+k_{2} \alpha_{R}^{2}\right)}{\partial \alpha_{R}}=k_{1}+2 k_{2} \alpha_{R}<0$. (c) If the quadratic function has a u-shape, $k_{2}>0$, then the quadratic function has a negative value at $\alpha_{R}=0$ and increases for larger $\alpha_{R}$. We show that the function has a negative value at $\alpha_{R}=1$ by noting that $k_{2} \geq 0$ implies $s \leq \frac{1}{2}$ and $k_{0} \leq 0$ implies $r \leq \frac{1}{2}$ and $s>\frac{(1-b)(1-r)}{1-2 r} . \mathrm{W} \log \beta_{R}=1$, then $k_{0}+k_{1}+k_{2}=[1-b-s(1+b)]-r[3-b-4(1+b) s]$ is linear in $r$ and is maximized at the boundary values $r=\left\{0, \frac{1}{2}\right\} \cdot{ }^{11}$ For $r=0$, we get $(1-b)-s(1+b)<s \frac{1-2 r}{1-r}-s(1+b)=-s \frac{b+r(1-b)}{1-r} \leq 0$, where we use $(1-b)<s \frac{1-2 r}{1-r}$. For $r=\frac{1}{2}$, we get $k_{0}+k_{1}-k_{2}=-\frac{(1+b)(1-2 s)}{2}<0$ where $r=\frac{1}{2}$ implies $s<\frac{1}{2}$. Hence, $k_{0}+k_{1}+k_{2} \leq 0$.

Proof of Corollary 2 follows as outlined in the text.

Proof of Proposition 3 We use $\frac{\partial M}{\partial I_{R}}=r \frac{M}{I_{R}}$ and $\frac{\partial M}{\partial I_{S}}=s \frac{M}{I_{S}}$, Equation (13), and Lemma 1

${ }^{10}$ Please note that the sign of $k_{2}$ alters the ordering of the zeros, $z_{1}$ and $z_{2}$.

${ }^{11}$ Formally, we can recast the quadratic function in terms of $z_{R}=\beta_{R} \alpha_{R}$ and determine the zero $\bar{z}_{R}$ and $\bar{\alpha}_{R}\left(\beta_{R}\right)=\bar{z}_{R} / \beta_{R}$. Since $\bar{\alpha}_{R}(1) \geq \bar{\alpha}_{R}\left(\beta_{R}\right)$ for all $\beta_{R}$, our result is valid for all $\beta_{R}$. 
to obtain

$$
\begin{aligned}
\frac{d V_{T}}{d \alpha_{R}} & =\left(\frac{\partial M}{\partial I_{R}}-w_{R}^{\prime}\right) \frac{\partial I_{R}}{\partial \alpha_{R}}+\left(\frac{\partial M}{\partial I_{S}}-w_{S}^{\prime}\right) \frac{\partial I_{S}}{\partial \alpha_{R}} \\
& =\left(1-\gamma-\alpha_{R} \beta_{R} \gamma\right) \frac{\partial M}{\partial I_{R}} \frac{\partial I_{R}}{\partial \alpha_{R}}+\gamma \frac{\partial M}{\partial I_{S}} \frac{\partial I_{S}}{\partial \alpha_{R}} \\
& \left.=\left(1-\gamma-\alpha_{R} \beta_{R} \gamma\right) \frac{r \frac{\partial I_{R}}{\partial \alpha_{R}}}{I_{R}}+\gamma \frac{\partial \frac{\partial I_{S}}{\partial \alpha_{R}}}{I_{S}}\right) M \\
& =P\left(\alpha_{R}\right) \frac{\beta_{R} M}{(1-r-s)\left(1+\alpha_{R} \beta_{R}\right)\left(1+b \alpha_{R} \beta_{R}\right)^{2}}
\end{aligned}
$$

where $P\left(\alpha_{R}\right)=c_{0}+c_{1} \alpha_{R}+c_{2} \alpha_{R}^{2}+c_{3} \alpha_{R}^{3}$ denotes a cubic function with coefficients $c_{0}=(2-$ b) $(1-b) r+r s(4 b-2)-s b^{2}, c_{1}=-(2 b s+r(1-2 s-4 b s)) b \beta_{R}, c_{2}=-(b s+r(2-2 s-4 b s)) b \beta_{R}^{2}$, and $c_{3}=r(2 s-1) b^{2} \beta_{R}^{3}$.

For $s \neq \frac{1}{2}$, the discriminant, $\Delta=18 c_{0} c_{1} c_{2} c_{3}-4 c_{2}^{3} c_{0}+c_{2}^{2} c_{1}^{2}-4 c_{1}^{3} c_{3}-27 c_{3}^{2} c_{0}^{2}>0$, is positive and the cubic function has 3 different real zeros, $\widehat{z}_{1 / 2 / 3}$, and two critical values, $\alpha_{1 / 2}^{\text {crit }}=-\frac{c_{2}^{+} \sqrt{c_{2}^{2}-3 c_{1} c_{3}}}{3 c_{3}}$, with $P^{\prime}\left(\alpha_{1 / 2}^{\text {crit }}\right)=0$. Wlog we assume

$$
\widehat{z}_{3}<\alpha_{2}^{\text {crit }}<\widehat{z}_{2}<\alpha_{1}^{\text {crit }}<\widehat{z}_{1}
$$

(i) Assume a positive intercept, $c_{0}>0$. This implies $c_{2}<0$ and three cases emerge: (a) For $c_{3}<0$, the cubic function has positive values within $\left(-\infty, \widehat{z}_{3}\right)$ and $\left(\widehat{z}_{2}, \widehat{z}_{1}\right)$. Since $\alpha_{2}^{\text {crit }}=$ $\frac{-c_{2}+\sqrt{c_{2}^{2}-3 c_{1} c_{3}}}{3 c_{3}}$ is negative (note that $c_{2}<0$ ), the positive intercept must lie in the interval $\left(\widehat{z}_{2}, \widehat{z}_{1}\right)$ and $\alpha_{R}^{T}=\widehat{z}_{1}$. (b) For $c_{3}>0$, the cubic function has positive values within $\left(\widehat{z}_{3}, \widehat{z}_{2}\right)$ and $\left(\widehat{z}_{1}, \infty\right)$ and has a negative value at $\alpha_{1}^{\text {crit }}$, i.e., $P\left(\alpha_{1}^{\text {crit }}\right)<0$. Since $\alpha_{1}^{\text {crit }}=\frac{-c_{2}+\sqrt{c_{2}^{2}-3 c_{1} c_{3}}}{3 c_{3}}$ is positive (note that $c_{2}<0$ ), we get $\alpha_{R}^{T}=\widehat{z}_{2} \cdot{ }^{12}$ (c) For $c_{3}=0$, the cubic function collapses to an inverse $u$-shaped quadratic function with a positive intercept and two zeros, $\widetilde{z}_{1}>\widetilde{z}_{2}$, implying that $\alpha_{R}^{T}=\widetilde{z}_{1} \cdot{ }^{13}$

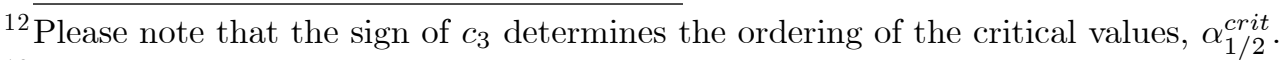

${ }^{13}$ Note that the quadratic function cannot reduce to a linear function as $c_{0}>0$ implies $c_{2}<0$.
} 
Noting that $c_{3}=0$ if $s=\frac{1}{2}$, our findings for $\bar{\alpha}_{R}$ can be summarized as follows:

$$
\bar{\alpha}_{R}=\left\{\begin{array}{rr}
\min \left\{\widehat{z}_{2}, 1\right\} & \text { if } s>\frac{1}{2} \\
\min \left\{\widehat{z}_{1}, 1\right\} & \text { if } s<\frac{1}{2} \\
\min \left\{\widetilde{z}_{1}, 1\right\} & \text { if } s=\frac{1}{2}
\end{array}\right.
$$

Finally, $c_{0}>0$ if $r>\frac{b^{2}}{(1-b)(2-b)+s(4 b-2)} s$, where $s<\frac{(1-b)(2-b)}{2-4 b}$ ensures a positive denominator if $b<\frac{1}{2}$.

(ii) Assume a negative intercept, $c_{0}<0$, i.e., $r \leq \bar{r}=\frac{b^{2} s}{(1-b)(2-b)+s(4 b-2)} \geq 0$ and $\bar{r} \geq 0$. We use these slightly different conditions for technical reasons. Further $c_{0}<0$ implies $c_{1}<0$. Three cases emerge: (a) For $c_{3}<0$, the cubic function has negative values within $\left(\widehat{z}_{3}, \widehat{z}_{2}\right)$ and $\left(\widehat{z}_{1}, \infty\right)$ and has a positive value at the critical value $\alpha_{1}^{c r i t}=\frac{-c_{2}-\sqrt{c_{2}^{2}-3 c_{1} c_{3}}}{3 c_{3}} \in\left(\widehat{z}_{2}, \widehat{z}_{1}\right)$, i.e., $P\left(\alpha_{1}^{\text {crit }}\right)>0$. Notice, $\alpha_{1}^{\text {crit }} \leq 0$ since $\alpha_{1}^{\text {crit }}>0$ implies $\sqrt{c_{2}^{2}-3 c_{1} c_{3}}>-c_{2}$ and $-3 c_{1} c_{3}>0$, contradicting $c_{1} c_{3} \geq 0$. Since $\alpha_{1}^{\text {crit }} \leq 0$ and the cubic function has a negative value at the intercept, we know that $\widehat{z}_{1}<0$. (b) If $c_{3}>0$, then the cubic function has negative values within $\left(-\infty, \widehat{z}_{3}\right)$ and $\left(\widehat{z}_{2}, \widehat{z}_{1}\right)$. Since the critical values satisfy $\alpha_{1}^{\text {crit }}>0>\alpha_{2}^{\text {crit }}, \widehat{z}_{1}$ can lie within $[0,1]$. However, we will show that $P(1)<0$, implying that $\widehat{z}_{1}>1 .{ }^{14}$ To do so, note that $P(1)$ is linear in $r$,

$$
P(1)=r((2-6 b)+s(2+2 b)(5 b-1))-4 b^{2} s
$$

and has its maximum at the boundary value, $r=\{0, \bar{r}\}$. Further, $P(1)=-4 b^{2} s<0$ for $r=0$ and $P(1)=\left(s\left(3-4 b+5 b^{2}\right)-3+b-2 b^{2}\right) \frac{2 b^{2} s}{(1-b)(2-b)+s(4 b-2)}$ for $r=\bar{r}$. The first term, $\left(s\left(3-4 b+5 b^{2}\right)-3+b-2 b^{2}\right)$, is maximized by the largest value of $s$, i.e., $s=1-\bar{r}=1-\frac{b}{2}$, yielding $-\frac{5(1-b)^{2} b}{2} \leq 0$. Since $\frac{2 b^{2} s}{(1-b)(2-b)+s(4 b-2)}>0$, we get $P(1)<0$. (c) For $c_{3}=0$, the cubic function collapses to an inverse u-shaped quadratic function with a negative intercept and


decreases in $\beta_{R}$.
} 
exhibits negative values for $\alpha_{R} \in[0,1]$.

Finally, $c_{0}<0$ if $s>\frac{(2-b)(1-b)}{b^{2}+r(2-4 b)} r$, where $r<\frac{b^{2}}{4 b-2}$ ensures a positive denominator if $b>\frac{1}{2}$.

Derivation of Equation (25) Knowing (15), $\frac{\partial M}{\partial I_{R}}=\frac{r M}{I_{R}}$, (13) and Lemma 1, we show that, for $V_{S}=\left(1-\gamma\left(\alpha_{R}\right)\right) M\left(I\left(\alpha_{R}\right)\right)-w_{S}\left(I_{S}\left(\alpha_{R}\right)\right)$,

$$
\begin{aligned}
\frac{d V_{S}}{d \alpha_{R}} & =\left((1-\gamma) \frac{\partial M}{\partial I_{S}}-w_{S}^{\prime}\right) \frac{\partial I_{S}}{\partial \alpha_{R}}+(1-\gamma) \frac{\partial M}{\partial I_{R}} \frac{\partial I_{R}}{\partial \alpha_{R}}-\frac{\partial \gamma}{\partial \alpha_{R}} M \\
& =\left((1-\gamma) \frac{r}{I_{R}} \frac{\partial I_{R}}{\partial \alpha_{R}}-\frac{\partial \gamma}{\partial \alpha_{R}}\right) M \\
& =\left(2 r-b+(2 r-1) \beta_{R} b \alpha_{R}\right) \frac{\left(1-b \beta_{R}\right)(1-s)}{(1-r)\left(1+\alpha_{R} \beta_{R}\right)\left(1+b \alpha_{R} \beta_{R}\right)^{2}} M
\end{aligned}
$$

is linear in $\alpha_{R}$, implying $\alpha_{R}^{S}$ as outlined in the text.

Proof of Proposition 4 Applying Propositions 2 and 3, and Equation (25) proves the result.

Proof of Proposition 5 We consider the bargaining problem in (29). The first-order condition with respect to $\gamma_{R}$, gives us

$$
\begin{aligned}
\gamma_{R} & =\frac{1}{2}+\left(\frac{\alpha_{R} \widehat{\gamma}_{R}(\beta+\delta)}{1+\alpha_{R}(\beta+\delta)}-\frac{\alpha_{S} \widehat{\gamma}_{S}(\beta+\delta)}{1+\alpha_{S}(\beta+\delta)}\right) \frac{\widehat{M}}{2 M} \\
& +\frac{M-\widehat{M}}{2 M}\left(\frac{1+\alpha_{S} \beta}{1+\alpha_{S}(\beta+\delta)}-\frac{1+\alpha_{R} \beta}{1+\alpha_{R}(\beta+\delta)}\right)
\end{aligned}
$$

where we abbreviate $M(\widehat{I})$ as $\widehat{M}$. In equilibrium, the conjectures are correct, $\widehat{\gamma}_{R}=\gamma_{R}$, $\widehat{\gamma}_{S}=\gamma_{S}$ and $\widehat{M}=M$, and we get the equilibrium value $\gamma$ from (30) and the second-order condition is satisfied, i.e.,

$$
-\frac{\left(1+\left(\alpha_{R} \gamma_{S}+\alpha_{S} \gamma_{R}\right)(\beta+\delta)\right)^{2}}{\left(\gamma_{1 R} \gamma_{1 S}\right)^{\frac{3}{2}}} M \leq 0
$$


Exploiting $\frac{\partial M}{\partial I_{i}}=\frac{r M}{I_{i}}$, the marginal value can be restated as:

$$
\begin{aligned}
\frac{d V_{i}}{d \alpha_{i}} & =\left(\gamma_{i} \frac{\partial M}{\partial I_{i}}-w_{i}^{\prime}\right) \frac{\partial I_{i}}{\partial \alpha_{i}}+\frac{\partial \gamma_{i}}{\partial \alpha_{i}} M+\gamma_{i} \frac{\partial M}{\partial I_{j}} \frac{\partial I_{j}}{\partial \alpha_{i}} \\
& =-\alpha_{i}\left(\beta \gamma_{i}-\delta \gamma_{j}\right) \frac{\partial M}{\partial I_{i}} \frac{\partial I_{i}}{\partial \alpha_{i}}+\frac{\partial \gamma_{i}}{\partial \alpha_{i}} M+\gamma_{i} \frac{\partial M}{\partial I_{j}} \frac{\partial I_{j}}{\partial \alpha_{i}} \\
& =\left(-\alpha_{i}\left(\beta \gamma_{i}-\delta \gamma_{j}\right) \frac{r \frac{\partial I_{i}}{\partial \alpha_{i}}}{I_{i}}+\frac{\partial \gamma_{i}}{\partial \alpha_{i}}+\gamma_{i} \frac{\partial \frac{\partial I_{j}}{\partial \alpha_{i}}}{I_{j}}\right) M
\end{aligned}
$$

Using (30) and (32), we show that the marginal value is a rational function with a degree of four.

Under symmetry of $\alpha_{i}=\alpha_{j}$, (A15) reduces to

$$
\frac{d V_{i}}{d \alpha_{i}}=\frac{d_{0}+d_{1} \alpha_{i}-d_{2} \alpha_{i}^{2}}{(4-8 r)\left(1+\alpha_{i}(\beta-\delta)\right)\left(1+\alpha_{i}(\beta+\delta)\right)} M,
$$

with coefficients $d_{0}=(1-3 r)(\beta+\delta)+4 r^{2} \beta, d_{1}=((1-4 r) \beta+\delta)((1-2 r) \beta-\delta)$, and $d_{2}=((3-4 r) \beta-\delta) r\left(\beta^{2}-\delta^{2}\right)$. Note, $d_{2} \geq 0$ must be true since $d_{2} \leq 0$ would imply $r \geq \frac{3 \beta-\delta}{4 \beta}>\frac{3 \beta-\beta}{4 \beta}=\frac{1}{2}$, contradicting $r<\frac{1}{2}$. Also, $d_{0} \geq 0$ is true as for $r>\frac{1}{3}$ we get $d_{0}>(1-3 r) 2 \beta+4 r^{2} \beta$ since $\beta>\delta$. Further, $(2-6 r) \beta+4 r^{2} \beta>0$ holds true for $r<\frac{1}{2}$. Finally, $d_{0}, d_{2} \geq 0$ implies $\bar{\alpha}_{i}=\frac{d_{1}+\sqrt{d_{1}^{2}+4 d_{0} d_{2}}}{2 d_{2}}$.

Proof of Corollary 3 We determine the marginal value of the supply chain through the first-order conditions (31), and obtain

$$
\frac{\partial V_{T}}{\partial \alpha_{i}}=\sum_{i=R, S}\left(\frac{\partial M}{\partial I_{i}}-w_{i}^{\prime}\right) \frac{\partial I_{i}}{\partial \alpha_{i}}=\sum_{i=R, S} \frac{1-\alpha_{i}(\beta-\delta)}{2} \frac{\partial M}{\partial I_{i}} \frac{\partial I_{i}}{\partial \alpha_{i}}
$$

which implies $\frac{\partial V_{T}}{\partial \alpha_{i}} \geq 0$ for $\alpha_{i} \leq \frac{1}{\beta-\delta}$. First-best would require $\alpha_{i}=\frac{1}{\beta-\delta}>1$. 


\section{References}

[1] Anctil, R., and Dutta, S. (1999). Negotiated transfer pricing and divisional vs. firm-wide performance evaluation. Accounting Review, 74(1), 87-104.

[2] Arya, A., Fellingham, J., Glover, J., and Sivaramakrishnan, K. (2000). Capital budgeting, the hold-up problem, and information system design. Management Science, 46(2), 205-216.

[3] Baldenius, T., and Reichelstein, S. (1999). Negotiated versus cost-based transfer pricing. Review of Accounting Studies, 2(4), 67-91.

[4] Dutta, S., and Nezlobin, A. (2019). Mandatory disclosure, corporate investment, and shareholder welfare. Working Paper Berkeley.

[5] Edlin, A., and Reichelstein, S. (1996). Holdups, standard breach remedies, and optimal investment. American Economic Review, 86(3), 478-501.

[6] Fudenberg, D., and Tirole, J. (1986). A "signal-jamming" theory of predation. Rand Journal of Economics, 17(3), 366-376.

[7] Gibbons, R. (1985). Incentives in internal labor markets, mimeo.

[8] Grossman, S., and Hart, O. (1986). The costs and benefits of ownership: a theory of vertical and lateral integration. Journal of Political Economy, 94(4), 691-719.

[9] Hart, O. (1995). Firms, contracts, and financial structure. New York: Oxford University Press.

[10] Hart, O., and Moore, J. (1999). Foundations of incomplete contracts. Review of Economic Studies, 66(1), 115-138.

[11] Holmstrom, B. (1982). Managerial incentive problems: a dynamic perspective. In Essays in Economics and Management in Honor of Lars Wahlbeck. Helsinki: Swedish School of Economics. 
[12] Kanodia, C. and Sapra, H. (2016). A real effects perspective to accounting measurement and disclosure: implications and insights for future research. Journal of Accounting Research, 54(2), 623-676.

[13] Lai, G., Debo, L., and Nan, L. (2011). Channel stuffing with short-term interest in market value. Management Science, 57(2), 332-346.

[14] Lai, G., Xiao, W., and Yang, J. (2012). Supply chain performance under market valuation. Management Science, 58(10), 1933-1951.

[15] Lai, G., and Xiao, W. (2017). Inventory decisions and signals of demand uncertainty to investors. Manufacturing \& Service Operations Management, 20(1), 113-129.

[16] Liang, P., and Wen, X. (2007). Accounting measurement basis, market mispricing, and firm investment efficiency. Journal of Accounting Research, 45(1), 155-197.

[17] Noldeke, G., and Schmidt, K. (1995). Option contracts and renegotiation: a solution to the hold-up problem. RAND Journal of Economics, 26(2), 163-179.

[18] Segal, I., and Whinston, M. (2012). Property rights. The Handbook of Organizational Economics. Princeton: Princeton University Press.

[19] Schmidt, W., Gaur, V., Lai, R., and Raman, A. (2015). Signaling to partially informed investors in the newsvendor model. Production and Operations Management, 25(3), 383-401.

[20] Smith, J. (2018). Home Depot sets $\$ 1.2$ billion supply-chain overhaul. The Wall Street Journal. https://www.wsj.com/articles/home-depot-sets-1-2-billion-supplychain-overhaul-1528739061.

[21] Stein, J. (1989). Efficient capital markets, inefficient firms: a model of myopic corporate behavior. Quarterly Journal of Economics, 104(4), 655-670. 
[22] Taylor, T., and Plambeck, E. (2007). Supply chain relationships and contracts: the impact of repeated interaction on capacity investment and procurement. Management Science, 53(10), 1577-1593.

[23] Trefis Team (2018). Why is Home Depot making a considerable investment in its supply chain? Forbes. https://www.forbes.com/sites/greatspeculations/2018/06/13/whyis-home-depot-making-a-considerable-investment-in-its-supply-chain/\#65530c3a4a2b. 